\title{
Acute Myeloid Leukemia with inv(3) (q21.3;q26.2); GATA2, MECOM
}

National Cancer Institute

\section{Source}

National Cancer Institute. Acute Myeloid Leukemia with inv(3) (q21.3;926.2); GATA2,

MECOM. NCI Thesaurus. Code C122716.

An acute myeloid leukemia associated with inv(3)(q21.3q26.2) resulting in the reposition of a distal GATA2 enhancer to activate MECOM expression. It may present de novo or follow a myelodysplastic syndrome. The clinical course is aggressive. 